\title{
The environmental life cycle assessment of different electricity options in Kuwait
}

\author{
Mohammad Abotalib*, Jaya Jacob**, Hamid Alhamadi*** and Dhary Alkandari* \\ *Assistant Professor, Department of Earth and Environmental Science, Kuwait University, Khaldiya Campus, Kuwait \\ **Chemist, Department of Earth and Environmental Science, Kuwait University, Khaldiya Campus, Kuwait \\ ***Assistant Professor, Department of Computer Science, Kuwait University, Khaldiya Campus, Kuwait \\ *Corresponding Author: Mohammad.abotalib@ku.edu.kw
}

Submitted: $03 / 03 / 2020$

Revised: $\quad 08 / 02 / 2021$

Accepted: 14/02/2021

\begin{abstract}
In Kuwait, electricity is generated from two primary sources, heavy fuel combustion and natural gas combustion. As Kuwait relies mainly on petroleum-based products for electricity generation, identifying and understanding the environmental and energy trade-off of such operations should be carefully investigated. The life cycle assessment (LCA) tool is applied to identify the potential environmental impacts and energy performance of electricity generation under three scenarios, by considering the material flow in various stages involved such as raw-material extraction, transportation, and operations. The three scenarios investigated represent current and futuristic electricity grid mixes. The analysis of four indicators consists of two environmental and two energy indicators per one kWh of the electricity generated.

The environmental indicators examined are global warming potential (GWP) and water consumption (WC), whereas the energy indicators target cumulative energy demand (CED) and net energy ratio (NER). Results indicate that one $\mathrm{kWh}$ of electricity generated would have a GWP (0.63-0.77) $\mathrm{kg} \mathrm{CO}_{2}$-eq, mainly from the fuel combustion process, WC (0.0013-0.0015) $\mathrm{m}^{3}$ of water, about $68 \%$ from cooling processes, CED (9.9-10.7) MJ, and NER (0.34-0.39). The variation in results depends on the scenario investigated. It can be observed from the analysis that introducing solar photovoltaic and wind to the electricity grid mix improves the environmental and energy performance of Scenarios 3 , where $15 \%$ of the electricity generated from renewables (10\% solar PV and $5 \%$ wind) corresponds to a further decrease in LCA results.
\end{abstract}

Keywords: Energy; Functional Unit; Global Warming Potential; Life Cycle Assessment.

\section{INTRODUCTION}

Globally, the demand for electricity is expected to increase, mainly due to population and economic growth. According to British Petroleum (BP), the world economy is expected to double in the next two decades, and this growth will electrify the energy consumption, mainly used for power generation (British Petroleum, 2017). In Kuwait, the electricity production has doubled from the year 2000 baseline reaching 54 million kWh in 2014 (CIA, 2015). Kuwait is a small country with a total population of 4.5 million; however, the energy consumption per capita is considered as one of the highest in the world (International Energy Agency (International Energy Agency (IEA), 2017; PACI, 2018)). This high consumption can be explained by three main factors. The first factor is the subsidized price of electricity for both public and private sectors. Second, the rapid annual population growth, which is about 3.3\% increase (Alotaibi, 2011). Third, the long summer season, which can last for more than seven months, and therefore, increasing the need 
for continuous operations of air condition (Al-Mutairi, Smallbone, Al-Salem, \& Roskilly, 2017). According to Reicher 2010, Kuwait and other GCC countries are accountable for producing the highest amount of carbon dioxide per capita worldwide (Reiche, 2010). In Kuwait, an overwhelming one-third to one-half of the oil produced is consumed by the cogeneration of electricity and water desalination (Darwish, Al-Awadhi, \& Darwish, 2008; Fattouh \& Mahadeva, 2014; KEPA, 2015). In Kuwait, electricity is produced by seven power plants as illustrated in Table 1. Older power plants use fuel oil as a primary fuel; however, more recent facilities have been designed to operate on gas oil and natural gas (Al Jandal \& Al Sayegh, 2015). Some of these power plants are designed to serve the purpose of electricity generation, as well as seawater desalination for potable use (Al Jandal \& Al Sayegh, 2015).

Energy-intensive desalination plants (DPs) result in huge ecological and health impacts that need more comprehensive assessment (Al-Abdulghani, El-Sammak, \& Sarawi, 2013; Aleisa, Al-Ahmad, \& Taha, 2011). However, some power plants generate electricity, as well as water, and combine two or more thermodynamic cycles, resulting in improved overall efficiency, reducing fuel costs. The most common desalination techniques used in Kuwait are multistage flashing (MSF) desalination technique and reverse osmosis (RO). The desalination of seawater till a few years back was accomplished in seven distillation and power plants (Al-Mutairi et al., 2017). The distillation units in these power stations use the MSF evaporation method, and the capacity of the units was between 0.023 to $0.027 \mathrm{Mm}^{3} / \mathrm{d}(\mathrm{Oyoh}$, 2017). Each of the distillation units consists of several stages ranging from 24 to 26 stages. The total capacity of the distillation units in the power and water distillation stations was $1.175 \mathrm{Mm}^{3} / \mathrm{d}$ (Oyoh, 2017).

Table 1. List of power plants in the State of Kuwait.

\begin{tabular}{|c|c|c|c|c|c|c|}
\hline & Power Plants Name & Capacity in MWe & $\begin{array}{l}\text { Desalinated } \\
\text { Water(MIG) }\end{array}$ & Technology & Primary fuel & $\begin{array}{l}\text { Secondary } \\
\text { fuel }\end{array}$ \\
\hline 1 & Shuwaikh & 252 & 10047 & Open cycle gas turbine & Natural gas & - \\
\hline 2 & Shuaiba North & 876 & 10297 & $\begin{array}{l}\text { Power and desalination } \\
\text { combined cycle gas turbine }\end{array}$ & Natural gas & Gas oil \\
\hline 3 & Shuaiba South & 720 & 8907 & $\begin{array}{l}\text { Power and desalination } \\
\text { combined cycle gas turbine }\end{array}$ & Natural gas & Gas oil \\
\hline 4 & Doha East & 1158 & 12115 & $\begin{array}{l}\text { Cogeneration power and } \\
\text { desalination steam turbine }\end{array}$ & $\begin{array}{l}\text { Heavy fuel oil, } \\
\text { crude oil, gas oil }\end{array}$ & Natural gas \\
\hline 5 & Doha West & 2360 & 33677 & $\begin{array}{l}\text { Cogeneration power and } \\
\text { desalination steam turbine }\end{array}$ & $\begin{array}{l}\text { Heavy fuel oil, } \\
\text { crude oil, gas oil }\end{array}$ & Natural gas \\
\hline 6 & Al-Zour & 5306 & 48195.82 & $\begin{array}{l}\text { Open and combined cycle gas } \\
\text { turbine }\end{array}$ & $\begin{array}{l}\text { Natural gas and } \\
\text { gas oil }\end{array}$ & - \\
\hline 7 & Sabiya & 4867 & 32736 & $\begin{array}{l}\text { Power and desalination } \\
\text { combined cycle gas turbine }\end{array}$ & $\begin{array}{l}\text { Heavy fuel oil, } \\
\text { crude oil, gas oil }\end{array}$ & Natural gas \\
\hline
\end{tabular}

Adopted from (Al-Mutairi et al., 2017).

As illustrated in Table 1, fossil fuel such as crude oil, natural gas, and gas oil is the backbone fuel of the current power plants in Kuwait. Therefore, future expansion projects should consider additional capacity from nonconventional sources to grow in line with goals of sustainable development. The new vision of 'Kuwait 2035' incorporates a matrix of seven pillars that include effective public administration, sustainable diverse economy, enhanced infrastructure, sustainable living environment, high quality health care, creative human capital, and enhanced global position (NewKuwait, 2018). Accordingly, Kuwait's 2035 strategy incorporated the use of renewable energy by $15 \%$ of country's total power capacity (Tortell \& Al-Essa, 2011; UNDP, 2014). To invest in Renewable Energy Technologies (RET) implies reducing the impact of meeting the national demand and the escalating consumption patterns. Energy created from RETs could gradually substitute oil and natural sources and therefore extend the lifeline of the country's nonrenewable resources. Hence, it is about time for the state of Kuwait to understand the environmental profile of the existing and proposed electricity generation practices to make informed strategic decisions about the future choices of electricity conversion technologies. In many situations, most practices or operations do not have immediate local or global environmental implications. Consequently, the decision-making process should address those problems in depth by considering the various technical and geographical variables. This matter has always been a challenging task for policy makers, as decisions are made based on incomplete information. This problem can underestimate or overestimate the magnitude of the situation (Miettinen \& Hämäläinen, 1997). In view of that, environmentalists have developed several environmental accounting tools, which can assist in making informed decisions. Among the tools developed is the life cycle assessment (LCA), which is described as an environmental decision-making tool 
for assessing the potential environmental impacts of a product or service, by accounting for the material flows in every process or stage such as raw-material extraction, transportation, operations, and waste disposal (Bare, 2011). In 2006, the International Standards Organization (ISO) has developed the ISO-14040 series of standards, systematic guidelines for LCA practitioners, which define a clear set of guidelines for conducting LCA studies (ISO, 2006). The basis of LCA analysis identifies system boundaries of the electricity produced as the product and covers processes including fuel supply, fuel transportation, and fuel combustion (i.e., fuel conversion to electricity). Similarly, the National Energy Technology Laboratory (NETL) suggested an approach, which covers important stages starting from material acquisition to electricity end users (NETL, 2010).

In recent years, the LCA tool has been supported by researchers from various fields, including those interested in evaluating the environmental impacts of electricity generation (Lee, Lee, \& Hur, 2004). Several LCA studies have already been carried out, which have evaluated the environmental impacts associated with electricity generation in different countries including the United States, the United Kingdom, Germany and China (Cui-Cui, Mei, Pei-Pei, \& An-Na, 2013; Di, Nie, Yuan, \& Zuo, 2007; EURELECTRIC, 2011; Lee et al., 2004; Reiche, 2010; Stamford \& Azapagic, 2014; UChicago Argonne, 2014). In these studies, results have shown wide range of variability because these studies have used inconsistent parameters, as well as different electricity grid mix. This is because each country has a different electricity grid mix profile due to various economic, geographic, and political factors. For example, in Scandinavia, the electricity mix portfolio is more diverse consisting of fair shares of hydro-, geothermal, wind, solar, and nuclear power (IEA, 2017). However, this not the case for oil wealthy nations, like Kuwait, where petroleumbased products are considered the primarily fuel used for electricity generation (IEA, 2017). Another study published by Turconi et al. (2013) reviewed 167 LCA case studies of various electricity generation technologies including fossil fuel-based and renewable energy technologies. The results suggest that it is not sufficient to focus on a single environmental impact indicator to make informed environmental decisions. However, these studies agreed on the fact that fossil fuel-based technologies have their highest GHG emissions during the plant operation phase. On the other hand, the manufacturing and infrastructure phases represent the highest GHG emissions for renewable technologies. Still, the methodology is applied, and the system boundaries play a fundamental role in the LCA results. Accordingly, the environmental friendliness of a specific electricity generation technology depends on various parameters such as source of energy, fuel type, and energy conversion techniques. So far, the LCA of Kuwait's electricity generation has not been evaluated.

To make such informed evaluation, it is necessary to identify the existing electricity grid mix profile with a comprehensive understanding of technologies adopted and the type and the source of fuel used. We will apply the LCA approach to calculate the environmental profile and energy performance of electricity generation in the state of Kuwait (per unit of electricity generated), which accounts for these considerations. The analysis will cover three scenarios. Scenario 1 represents the current electricity grid mix. Scenario 2 represents current electricity grid mix and extends the system boundary by assigning a displacement value for desalinated water, which is a coproduct of power plants. Scenario 3 is the same as Scenario 1; however, it considers a future scenario for electricity grid mix representing Kuwait's electricity grid mix in 2030, which includes $15 \%$ renewables.

\section{POTENTIAL SOLAR AND WIND IN KUWAIT}

Kuwait has substantial wind capacity, and the highest potential wind energy found in this region is during summer (Al-Nassar, Alhajraf, Al-Enizi, \& Al-Awadhi, 2005). Kuwait has an average wind speed of 5m/s in regions like AlWafra and Al-Taweel, which is relatively good (Hajiah \& Sebzali, 2013). Also, Kuwait already has an existing 2.4MW Salmi Mini-windfarm, completed in 2013, which mainly serves telecommunication towers in remote areas and the fire brigade station in Salmi (Al-Nassar et al., 2005). The ever-increasing population in Kuwait has caused a major drawback to set up onshore wind farms due to urbanization resulting in the scarcity of free land, and hence, it opens doors to the possibility to set up offshore wind farms. On the other hand, Kuwait is abundant in solar energy with long summer season punctuated by dust storms where daily sunshine hours/year ranges from 7 to 12 and annual solar radiation from 2100 to $2200 \mathrm{~kW} / \mathrm{m} 2$ (Al-Nassar et al., 2005). 


\section{LCA METHOD AND SYSTEM BOUNDARIES}

The LCA approach implemented in this study follows the ISO 14040 series of standards. As a first step, it is important to define the goals and the scope of the study, as well as define the functional unit and the system boundary. For our study, the goal is to assess the environmental and energy performance of electricity generation in Kuwait, where the functional unit selected is one kWh of electricity generated and delivered to consumers. The LCA system boundary accounts for upstream emissions, such as emission associated with fuels supply and the manufacturing of different electricity conversion technologies, as well as operational consequences such as direct emission from fuel combustion. The system boundaries of the three scenarios investigated are illustrated in Figure 1. The system boundary of each scenario includes upstream processes including fuel supply, fuel transportation, and operational processes such as fuel combustion (i.e., fuel conversion to electricity). For oil and natural gas, the upstream processes account for the entire supply chain of crude oil and natural gas covering processes such as exploration, production, processing, the long-distance transport, and the regional distribution to power plants, whereas, for solar photovoltaic and wind, the upstream processes cover the material and energy used to manufacture the needed installations for generating electricity. The power loss from electricity distribution is considered outside the scope of this study. The life cycle inventory (LCI), the second step, was obtained from government publications and industrial data published by Thinkstep AG (MEW, 2017). The Gabi (v.8) LCA modeling software was used to convert the LCI into environmental impact assessment (LCIA) (Thinkstep, 2018). Technologies covered include conventional power conversion technologies such oil-field and natural gas combined cycle plants and nonconventional power conversion technologies such as solar photovoltaics and wind.

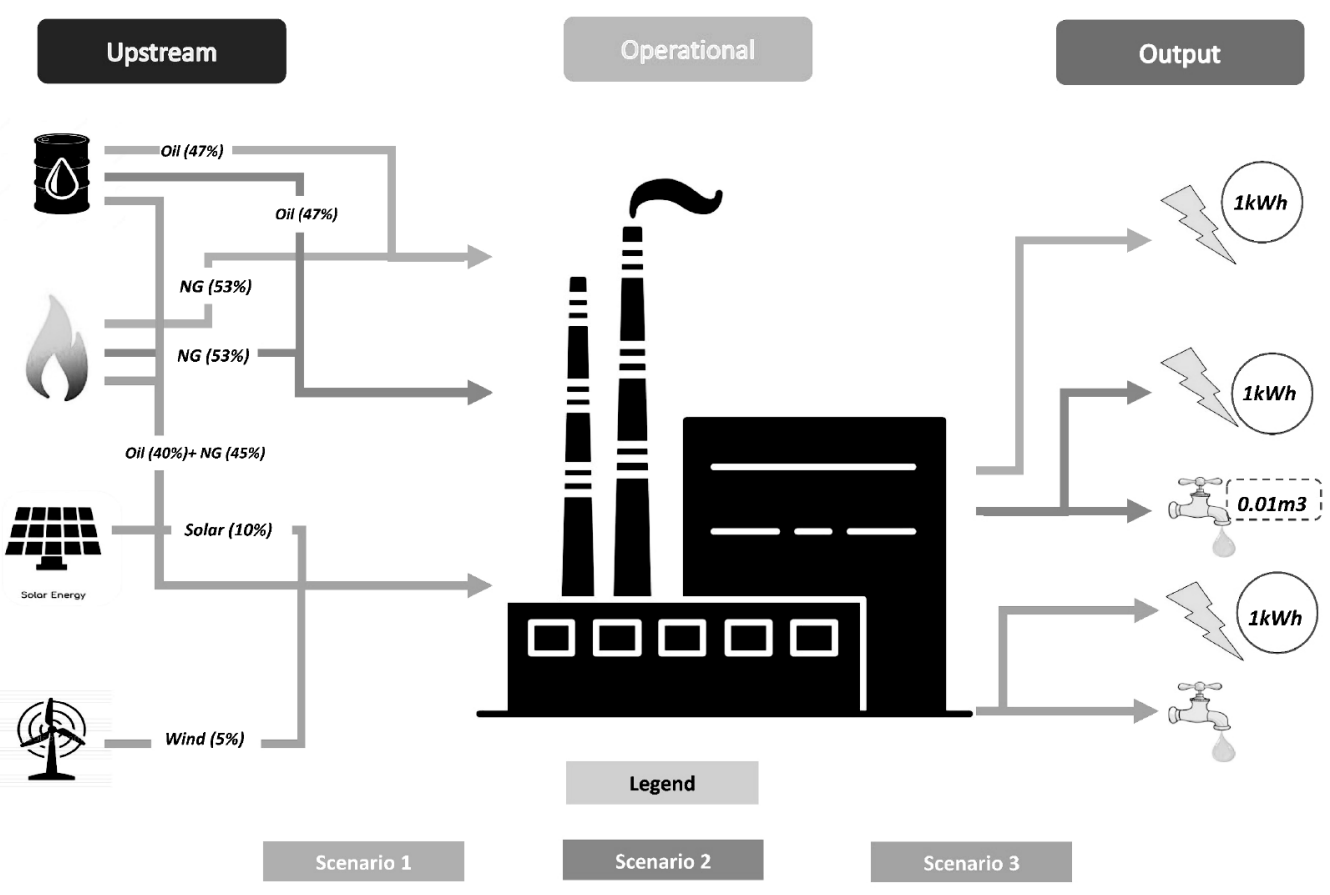

Figure 1. System boundaries for the three scenarios investigated for electricity generation in Kuwait.

\section{MODEL DESCRIPTION}

In our model, the functional unit defined is one $\mathrm{kWh}$ of electricity generated from power plants in Kuwait and delivered to consumers, as illustrated in Figure 1. Three scenarios are investigated, where Scenario 1 only considers electricity as the singular product of the system. On the other hand, Scenario 2 considers electricity as the main product of the of system and desalinated water as a coproduct of the system. Scenario 3 considers a future scenario 
for electricity grid mix representing Kuwait's electricity grid mix in 2030, which consists of an electricity grid mix of $40 \%$ oil-fired, $45 \%$ natural gas, $10 \%$ solar PV, and $5 \%$ wind.

Table 2. The environmental and energy indicators covered in this study.

\begin{tabular}{lll}
\hline Indicator & Formula & \multicolumn{1}{c}{ Description } \\
\hline Global warming potential (GWP) & $\mathrm{GWP}=\mathrm{C}_{\mathrm{r}, \mathrm{t}}$ & $\begin{array}{l}\mathrm{C}_{\mathrm{r}, \mathrm{t}} \text { the cumulative radiative forcing, both direct and } \\
\text { indirect effects over a specific time horizon (commonly } \\
100 \text { years) }\end{array}$ \\
& &
\end{tabular}
Water consumption (WC)
$\mathrm{WC}=\mathrm{C}_{\mathrm{w}}$
$\mathrm{C}_{\mathrm{w}}$ the cumulative water consumed

Cumulative energy demand (CED) $\quad \mathrm{CED}=\mathrm{Ec} / \mathrm{Eg} \quad \mathrm{Ec}$ is the energy consumed during the life cycle

(infrastructure, fuel supply, transport, processes) and the conversion losses through the electricity generation plant.

Eg is the energy generated per $\mathrm{kWh}$

Low CED means high energy efficiency

Net energy ratio $\quad \mathrm{NER}=\mathrm{Eg} / \mathrm{Ec} \quad \mathrm{Eg}$ is the energy generated per $\mathrm{kWh}$

Ec is the energy consumed during the life cycle (infrastructure, fuel supply, transport, processes) and the conversion losses through the electricity generation plant.

High ENR means high energy efficiency

Source: (IPCC, 2007; Raadal, Modahl, \& Bakken, 2012)

Environmental and energy indicators investigated include GWP, WC, CED, and NER. The calculation, in the case of GWP for example, is illustrated in

$\operatorname{Net} \operatorname{GWP}(x, y, z, w)=G W P_{x, y, x, w}+(-d c)=\left[k g C O_{2}\right.$ eq. per $\left.k W h\right]$

where

$\operatorname{GWP}(x, y, z, w)=\sum_{i=1}^{n} P_{i}=P_{1}+P_{2}+\cdots+P_{n} \quad\left[k g \mathrm{CO}_{2}\right.$ per $\left.k W h\right]$

$\mathrm{x}=$ Electricity from fuel oil

$\mathrm{y}=$ Electricity from natural gas

$\mathrm{z}=$ Electricity from solar PV

$\mathrm{w}=$ Electricity from wind

$\mathrm{P}_{1}=$ GWP fuel supply and transport (upstream); $\mathrm{P}_{2}=$ GWP electricity generation (operational); $\mathrm{dc}=$ displacement credit $\left[\mathrm{kg} \mathrm{CO} 2\right.$ per $\mathrm{m}^{3}$ of water desalinated].

$d c=[$ units of coproduct $] *\left(\frac{\text { GHG displaced product }}{\text { unit }}\right)$ 
Table 3. Coproduct displacement value from generating $0.01 \mathrm{~m}^{3}$ of water per $\mathrm{kWh}$ of electricity generated.

\begin{tabular}{ll}
\hline Coproduct (dc) & Value* \\
\hline GWP [kg CO2 eq.] & 0.035 \\
\hline Water Consumption [m3] & $6.97 \mathrm{E}-05$ \\
\hline CED [MJ] & 0.491 \\
\hline NER [kWh_g/kWh_cons] & 0.015 \\
\hline
\end{tabular}

*Values are calculated based on the energy required to produce $0.01 \mathrm{~m}^{3}$ of water desalinated.

${ }^{+} \mathrm{kWhg}$ is the electricity generated and available to the grid, and $\mathrm{kWh}$ cons is the $\mathrm{kWh}$ consumed to generate one $\mathrm{kWh}$ of electricity.

To calculate the results of environmental and energy indicators for each scenario, we used the ReCiPe method, integrated in GaBi software, developed by RIVM, CML, PRé Consultants, Radboud Universiteit Nijmegen, and CE Delft for life cycle impact assessment (LCIA) (Huijbregts et al., 2017)

\section{DATA SOURCES FOR LIFE CYCLE ASSESSMENT}

In the scenarios investigated, the required data for the LCI was obtained from government publications and industrial data published by Thinkstep AG in Gabi (v.8) database using regional specific operational parameters for Kuwait. The technologies technical performance parameters, which determine the resources needed to generate electricity, are shown in Table 4.

Table 4. Key technical and operational parameters of electricity conversion technologies.

\begin{tabular}{|c|c|c|c|c|}
\hline Parameter & Oil-fired & NG-fired & Solar & Wind \\
\hline Technology & Steam turbine & Combined cycle & $\begin{array}{l}\text { Photovoltaics Mix of } \\
\text { mono crystalline and } \\
\text { multi crystalline }\end{array}$ & $\begin{array}{l}\text { Mix of onshore and } \\
\text { offshore }\end{array}$ \\
\hline Efficiency & $36 \%$ & $40 \%$ & $\begin{array}{l}\text { Mono-Silicon } 14 \% \\
\text { Multi-Silicon } 13.2 \% \text {, }\end{array}$ & $40.8 \%$ \\
\hline $\begin{array}{l}\text { Production } \\
\text { and supply } \\
\text { covered }\end{array}$ & $95 \%$ & $95 \%$ & $95 \%$ & $95 \%$ \\
\hline Remarks & $\begin{array}{l}\text { The calculation } \\
\text { of LCI results } \\
\text { refers to net } \\
\text { calorific value. }\end{array}$ & $\begin{array}{l}\text { The calculation } \\
\text { of LCI results } \\
\text { refers to net } \\
\text { calorific value. }\end{array}$ & $\begin{array}{l}\text { End-of-Life of the } \\
\text { PV-modules is not } \\
\text { included in the LCA- } \\
\text { model. }\end{array}$ & $\begin{array}{l}\text { Processes covered } \\
\text { in the LCA includes } \\
\text { production, } \\
\text { transportation, } \\
\text { installation, } \\
\text { operation, } \\
\text { dismantling and } \\
\text { removal of the } \\
\text { wind turbines incl. } \\
\text { electrical gear. }\end{array}$ \\
\hline
\end{tabular}




\section{RESULTS}

The LCA results, henceforth, are illustrated in mass volume per one $\mathrm{kWh}$ of electricity produced and delivered to consumers in all investigated scenarios. The results for the environmental and energy indicators per kWh of electricity generated from different technologies are shown in Figure 2.

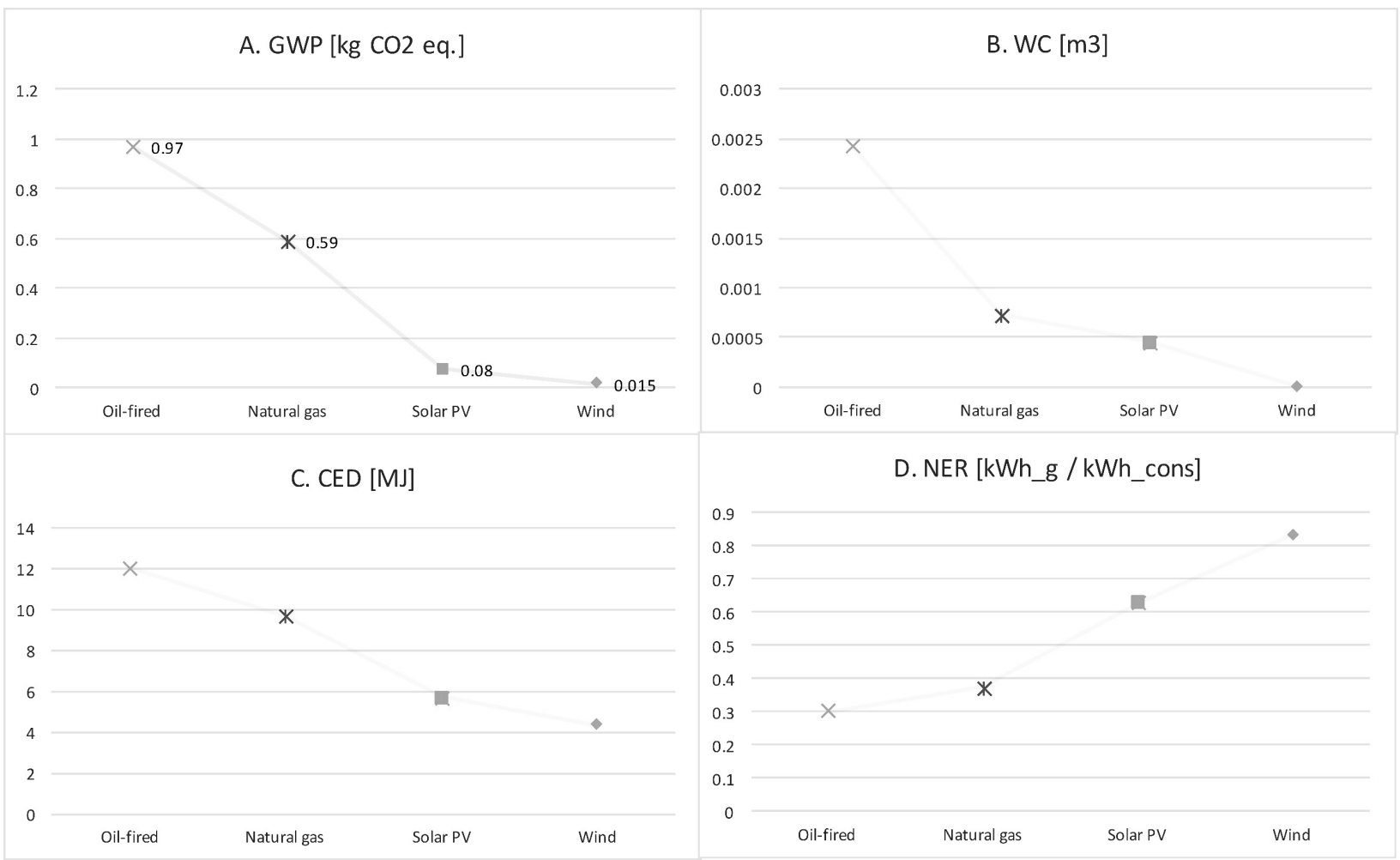

Figure 2. LCA results from different technologies considered in the analysis per kWh of electricity generated.

To further understand the relationship between efficiency, CED, and GWP, Figure 3 shows different technologies and compares their CED with efficiency, where the size of the symbol represents the GWP; that is, the larger the symbol, the greater the GWP.

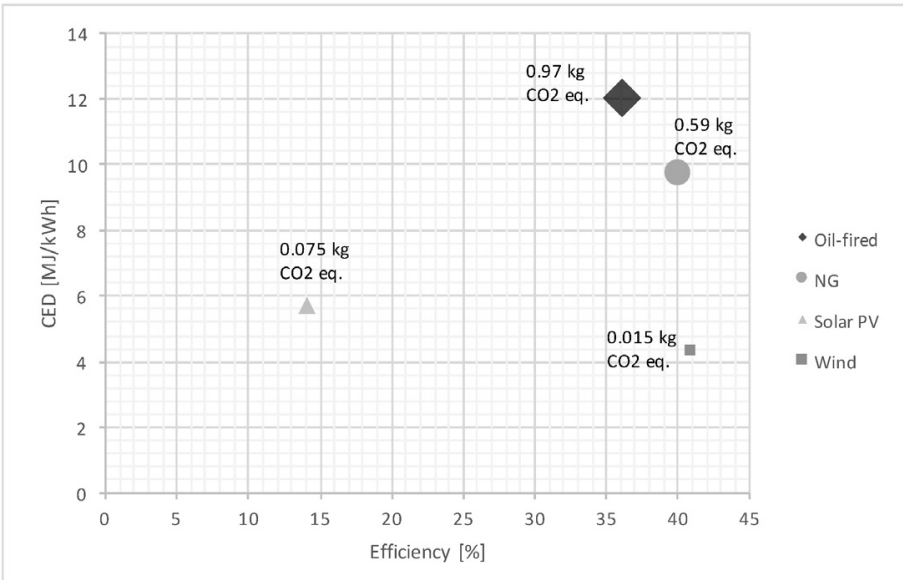

Figure 3. Relationship between technology efficiency CED and GWP for oil-fired, natural gas, solar PV, and wind. 
It can be seen from Figure 3 that wind and solar PV consume about half of the nonrenewable resources compared to oil-fired and natural gas technologies. Also, it can be observed that they have lower efficiency, and yet, they are still better than oil-fired and natural gas technologies with regard to their GWP per kWh of electricity generated. Even though wind and solar PV technologies do not generate any greenhouse gas emissions during their operations, trivial upstream emissions are generated during the production phase and the end of life phase.

Three scenarios were examined, representing different electricity generation cases illustrated in Figure 4.

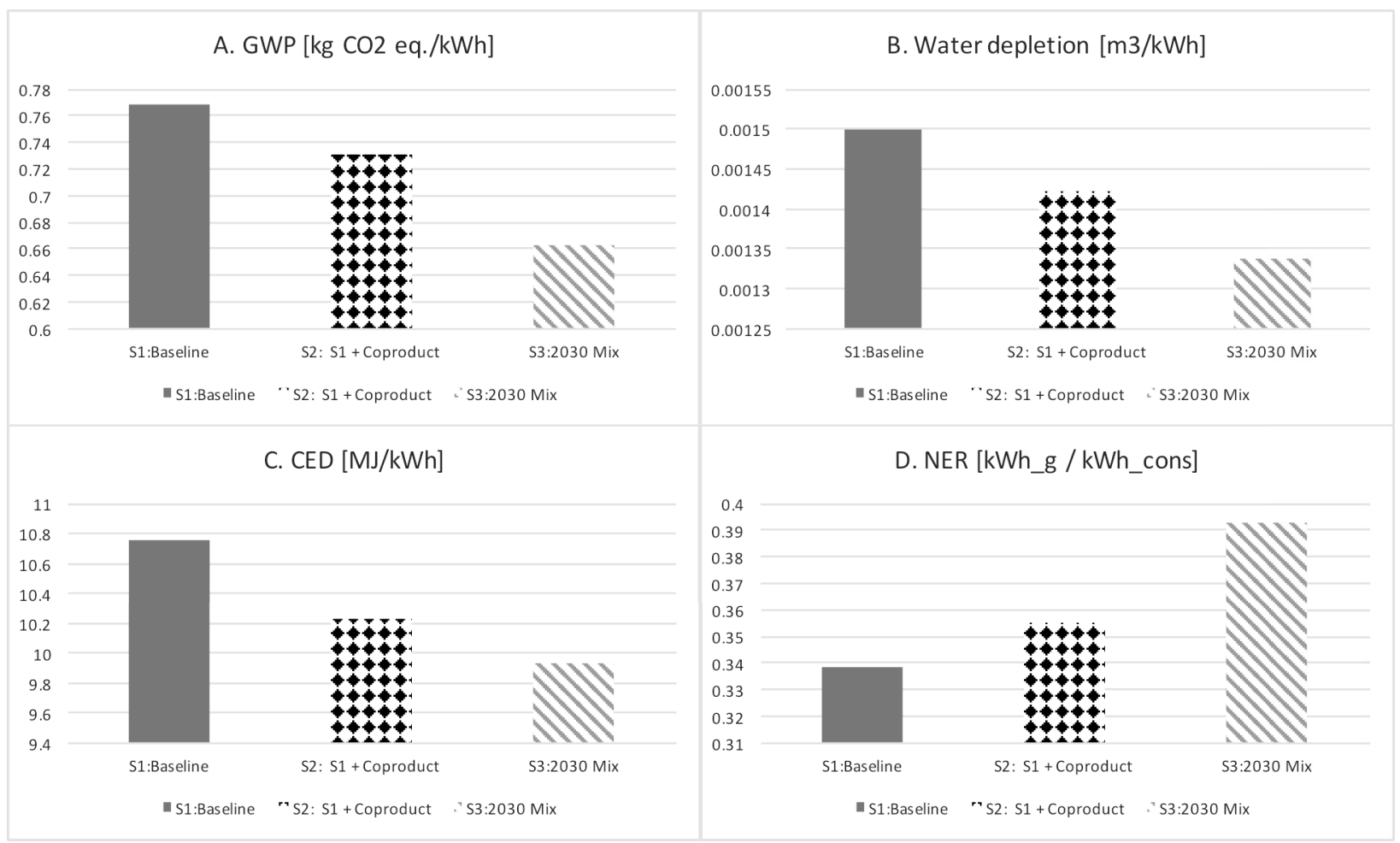

Figure 4. LCA characterization results of environmental impacts categories per kWh of electricity generated.

The scenarios were compared to the current electricity grid mix (Scenario 1), which has a GWP of $0.77 \mathrm{~kg} \mathrm{CO}_{2}$ eq./kWh, WC of $0.0015 \mathrm{~m}^{3} / \mathrm{kWh}, \mathrm{CED} 10.7 \mathrm{MJ} / \mathrm{kWh}$, and NER of 0.34 As shown in Figure 4, the LCA results varied among the investigated scenarios, where Scenarios 2 and 3 perform better than Scenario 1. The results in Scenario 2 suggest that using system expansion approach had slightly improved the environmental and energy performance by $5 \%$ compared to Scenario 1 as it distributes the environmental impacts over two products (electricity and water). In other words, Scenario 2 performs slightly better than Scenario 1 as it considered displacement credit for the water desalinated from the system (see the method section for details on system expansion). Furthermore, In Scenario 3, the results show more positive outcomes as GWP, WC, and CED were decreased by $14 \%, 11 \%$, and 8\%, respectively. Furthermore, the NER increased by $16 \%$. Therefore, it can be seen that Scenario 3 is the most preferred option compared to Scenarios 1 and 2. In view of that, introducing solar photovoltaic and wind to the electricity grid mix would improve the performance of Scenario 3 and correspond to a further decrease in LCA results of the investigated environmental impact categories. To further understand the contribution of the environmental impacts from various system processes, sensitivity analysis was carried out for GWP as shown in Figure 5. 


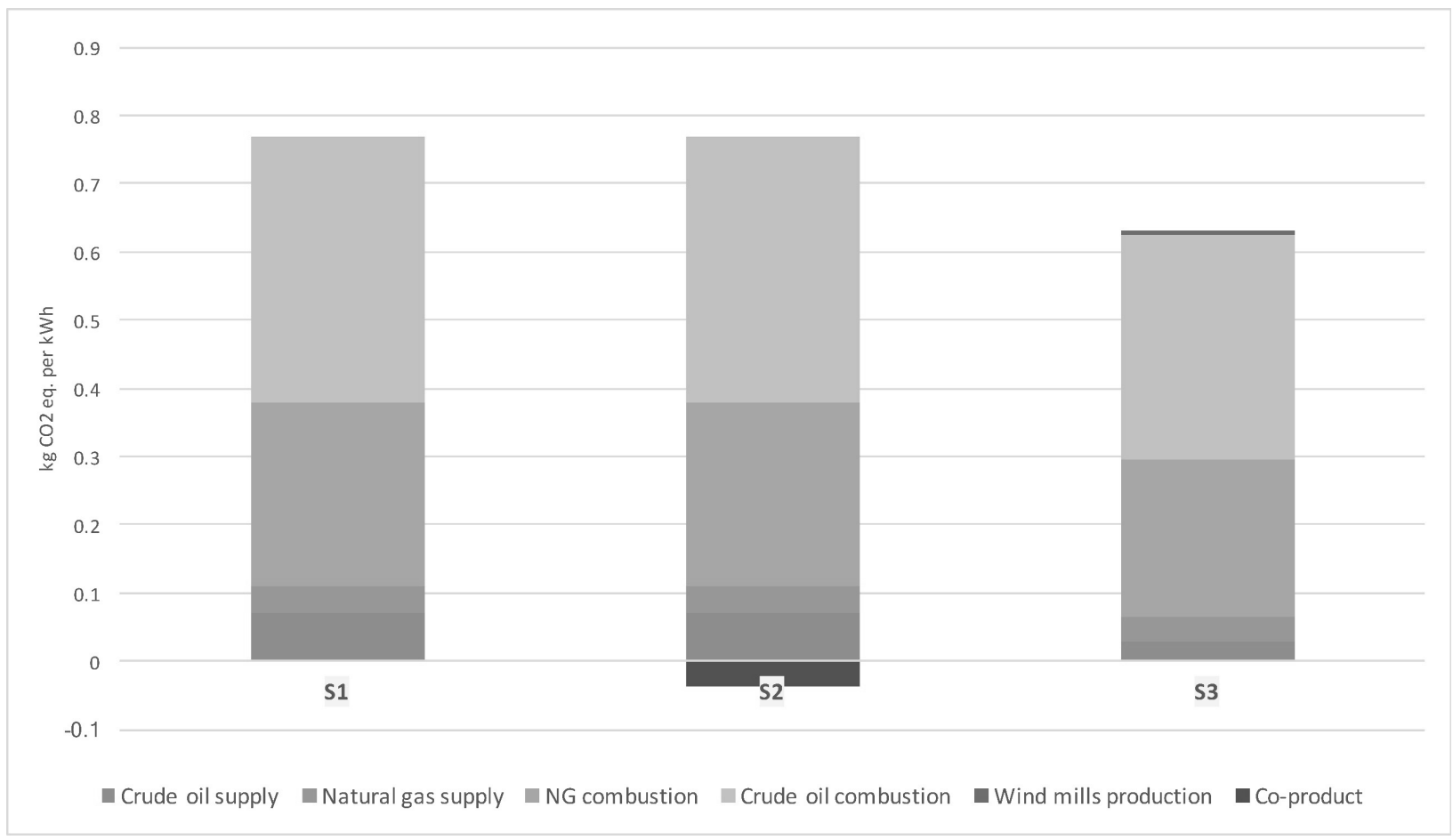

Figure 5. The contribution of GWP from different stages of LCA results for the three scenarios.

For example, the results of Scenarios 1, 2, and 3 were further investigated to identify the share of GWP from processes that have been included in the study system boundary. In Scenario 1, where only nonrenewable fuel was used for the electricity generation, it was found that $90 \%$ of the $\mathrm{CO}_{2}$ emissions were generated from the fuel combustion process. The remaining $10 \%$ occurred from the fuel supply and transportation system processes. Hence, adopting carbon capture and sequestration (CCS) technologies could make up to $90 \%$ reduction in the in $\mathrm{CO}_{2}$ emission from the fuel combustion process for fuel-based power plants. However, such application may have different effects on other environmental impacts categories depending on the selected CCS technology. Alternatively, replacing fuel oil can be replaced with natural gas as it has about $400 \mathrm{~g}$ of $\mathrm{CO}_{2}$ eq. per $\mathrm{kWh}$, which is about $50 \%$ less $\mathrm{GHG}$ emissions compared to fuel oil. However, switching to natural gas does not make a 50\% net GWP reduction because the fuel supply process of natural gas has about two-thirds of the $\mathrm{CO}_{2}$ emissions compared to crude oil.

\section{DISCUSSION AND CONCLUSION}

Renewables are a trivial contributor to Kuwait grid mix, whereas the share of fossil fuel technologies accounts for the largest share. Current power generation technologies are carbon and intensive energy, and the seawater desalination could pose some environmental and health concerns because the process generates some byproducts such as brine and hot water. In 2015, the carbon emissions from the power generation industry were approximately 34 million tons of CO2-eq., and this quantity is expected to double by 2030 (see system model for details). A similar increase is expected to take place for WC, CED, and NER. Therefore, a fast transition to renewables is vital to reduce these environmental indicators. Decarbonizing the global economy requires thoughtful long-term policies, which incorporates less carbon intensive energy sources. Results indicate that wind and solar PV are the most appropriate technologies, which will foster the transition towards a better environmentally friendly electricity grid mix in Kuwait.

In contrast, oil-fired and natural gas technologies consume greater amount of nonrenewable primary resources compared to renewable technologies such as solar PV and wind. Accordingly, the new GCC scheme reform commits 
to investing up to $\$ 100$ billion in renewable energy projects (REP) over the coming two decades (UNDP 2014). Investing in REP implies reducing the impact of carbon and the escalating consumption patterns while meeting the national demand. Energy created from renewables could gradually substitute crude oil and natural gas and therefore extend the lifeline of the country's fossil fuel resources for some decades. Hence, it is rational to switch and introduce RET to the current electricity grid mix, not only for environmental considerations, but also for sustainable growth. However, it is crucial to actively investigate and carefully analyze diverse renewable energy mixes according to availability, sustainability, durability, and efficiency (Cheng \& Hammond, 2017).

Despite the environmental benefits of renewable energy technologies, it is important to consider major concerns such as storage capabilities, hazardous waste generation, and geographic limitations (Hoffacker, Allen, \& Hernandez, 2017). In other words, making rational environmental and economic decisions requires a comprehensive understating of region-specific environmental conditions, not only considering immediate possible consequences, but also considering the potential long-term impacts. In Kuwait, where residential land is limited, it is essential to be mindful of the land footprint of renewables to achieve the dual objective of providing clean electricity and preserving valuable land for oil extraction, farming, or residential purposes (Sen, Onat, Kucukvar, \& Tatari, 2019). For example, building solar and wind farms in Kuwait mainland clearly creates a new form of competition for land. A study estimated that land use footprint for the installation of Concentrating Solar Power systems (CSP) farms in the US was $15 \mathrm{~m}^{2} / \mathrm{MWh}$ and $1 \mathrm{~m}^{2} / \mathrm{MWh}$ for wind. The same study estimated that fossil fuel-based technologies such as natural gas have about $0.2 \mathrm{~m}^{2} / \mathrm{MWh}$ (Fritsche et al., 2017).

Future studies should not only consider the environmental pillar of the LCA of electricity generation technologies, but also account for the socioeconomic aspect. Recent efforts have focused on integrating the three pillars of sustainability into a single framework, which complements the environmental LCA with life cycle cost assessment (LCC), and social life cycle assessment (S-LCA) (Onat, Aboushaqrah, Kucukvar, Tarlochan, \& Hamouda, 2020). With LCC and S-LCA, decision makers can better understand the economic cost and societal benefits of the various electricity generation technologies discussed in this study considering the different phases of life span of each power technology option such as the initial capital cost, cost of operation and maintenance (O\&M), and the end of life (Onat, Kucukvar, Aboushaqrah, \& Jabbar, 2019; Onat et al., 2020). Also, to further make more informed future energy policies, the integration of renewable energy policies and smart grid principles can be an extremely effective approach. The application of the smart grids would be extremely useful in providing information that can help in making more comprehensive analysis of the share of different power supply technologies. For example, using internet of things (IoT) advancements for renewable and nonrenewable energy generation in smart grids is invaluable as it considers gathering real-time data for decision-making and controlling and monitoring deployed equipment. More specifically, for renewable energy, upstream electricity generation can greatly benefit from real-time measurements of phenomena to optimize energy generation based on measured phenomena (e.g., enough sunlight and interfering dust for solar panels, and enough wind speed for wind turbines).

\section{ACKNOWLEDGMENT}

This work was funded by Kuwait University Research Sector (RS) under grant No. SE01/18. The author is grateful to the RS for supporting research among Kuwait University faculties.

\section{REFERENCES}

Al Jandal, S., \& Al Sayegh, O. (2015). Clean energy policy options; modeling possible deployment scenarios. EcoMod, 8920

Al-Abdulghani, E., El-Sammak, A., \& Sarawi, M. (2013). Environmental assessment of kuwait bay: An integrated approach. Journal of Coastal Conservation, 17(3): 445-462.

Aleisa, E., Al-Ahmad, M., \& Taha, A.M. (2011). Design and management of a sewage pit through discrete-event simulation. Simulation, 87(11): 989-1001.

Al-Mutairi, A., Smallbone, A., Al-Salem, S.M., \& Roskilly, A.P. (2017). The first carbon atlas of the state of kuwait. Energy, 
133: $317-326$.

Al-Nassar, W., Alhajraf, S., Al-Enizi, A., \& Al-Awadhi, L. (2005). Potential wind power generation in the state of kuwait. Renewable Energy, 30(14): 2149-2161.

Alotaibi, S. (2011). Energy consumption in kuwait: Prospects and future approaches. Energy Policy, 39(2): 637-643.

Bare, J. (2011). TRACI 2.0: The tool for the reduction and assessment of chemical and other environmental impacts 2.0. Clean Technologies and Environmental Policy, 13(5): 687-696.

British Petroleum. (2017). BP energy outlook 2017 edition.1

Cheng, V.K., \& Hammond, G.P. (2017). Life-cycle energy densities and land-take requirements of various power generators: A UK perspective. Journal of the Energy Institute, 90(2): 201-213.

CIA. (2015). The world factbook 2014-15. Central Intelligence Agency, United States: Government Printing Office.

Cui-Cui, F., Mei, S., Pei-Pei, Z., \& An-Na, G. (2013). A comparison of coal supply-demand in china and in the US based on a network model. Chinese Physics B, 22(10): 108901.

Darwish, M.A., Al-Awadhi, F.M., \& Darwish, A.M. (2008). Energy and water in kuwait part I. A sustainability view point doi:https://doi.org/10.1016/j.desal.2007.06.018

Di, X., Nie, Z., Yuan, B., \& Zuo, T. (2007). Life cycle inventory for electricity generation in china. The International Journal of Life Cycle Assessment, 12(4): 217.

EURELECTRIC. (2011). Life cycle assessment of electricity generation (EURELECTRIC Renewables Action Plan (RESAP) No. D/2011/12.105/53)Union of the Electricity Industry.

Fattouh, B., \& Mahadeva, L. (2014). Price reform in kuwait's electricity and water sector: Assessing the net benefits in the presence of congestion.

Fritsche, U.R., Berndes, B., Cowie, A.L., Dale, V.H., Kline, K.L., Johnson, F.X., et al. (2017). Sustainable energy options and implications for land use.

Hajiah, A., \& Sebzali, M. (2013). Optimal sizing of wind power systems in three high wind potential zones in kuwait for remote housing electrification. International Journal of Renewable Energy Research (IJRER), 3(1): 167-171.

Hoffacker, M.K., Allen, M.F., \& Hernandez, R.R. (2017). Land-sparing opportunities for solar energy development in agricultural landscapes: A case study of the great central valley, CA, united states. Environmental Science \& Technology, 51(24): $14472-$ 14482.

Huijbregts, M.A., Steinmann, Z.J., Elshout, P.M., Stam, G., Verones, F., Vieira, M., et al. (2017). ReCiPe2016: A harmonised life cycle impact assessment method at midpoint and endpoint level. The International Journal of Life Cycle Assessment, 22(2): 138-147.

International Energy Agency (IEA). (2017). Key world energy statistics. 2012. Retrieved 11/11, 2017, from http://www.iea.org/ publications/freepublications/publication/kwes

IPCC. (2007). The fourth assessment report of the intergovernmental panel on climate change No. 2007). Cambridge, UK and New York, NY.: Cambridge University Press.

ISO. (2006). Environmental management - life cycle assessment - Requirements and guidelines. (Guideline No. 14044). Geneva, Switzerland: International Organization for Standardization.

KEPA. (2015). Intended nationally determined contributions. State of Kuwait: Kuwait Environment Public Authority.

Lee, K., Lee, S., \& Hur, T. (2004). Life cycle inventory analysis for electricity in Korea. Energy, 29(1): 87-101.

MEW. (2017). Statistical year book. kuwait, 2017 No. 1). Kuwait: Ministry of Water and Electricity.

Miettinen, P., \& Hämäläinen, R.P. (1997). How to benefit from decision analysis in environmental life cycle assessment (LCA). European Journal of Operational Research, 102(2): 279-294.

NewKuwait. (2018). Kuwait national development plan.http://www.newkuwait.gov.kw/plan

Onat, N.C., Aboushaqrah, N.N., Kucukvar, M., Tarlochan, F., \& Hamouda, A.M. (2020). From sustainability assessment to 
sustainability management for policy development: The case for electric vehicles. Energy Conversion and Management, 216: 112937.

Onat, N.C., Kucukvar, M., Aboushaqrah, N.N., \& Jabbar, R. (2019). How sustainable is electric mobility? A comprehensive sustainability assessment approach for the case of Qatar. Applied Energy, 250: 461-477.

Oyoh, T.D. (2017). Desalination in water treatment and sustainability.

PACI. (2018). The public authority for civil information,statistics service system. Retrieved 01/11, 2017, from https://www.paci. gov.kw/stat/

Raadal, H.L., Modahl, I.S., \& Bakken, T.H. (2012). Energy indicators for electricity Production-Comparing technologies and the nature of the indicators energy payback ratio (EPR), net energy ratio (NER) and cumulative energy demand (CED).

Reiche, D. (2010). Energy policies of gulf cooperation council (GCC) countries—possibilities and limitations of ecological modernization in rentier states. Energy Policy, 38(5): 2395-2403.

Stamford, L., \& Azapagic, A. (2014). Life cycle sustainability assessment of UK electricity scenarios to 2070. Energy for Sustainable Development, 23: 194-211.

Thinkstep. (2018). GaBi software (8th ed.). Hauptstraße 111-113 70771 Leinfelden-Echterdingen Deutschland: Thinkstep AG.

Tortell, P., \& Al-Essa, M. (2011). Seeking sustainability and cost efficiency: A UNDP environment programme for kuwait. UNDP Country Programme Document (CPD), Kuwait Google Scholar,

UChicago Argonne, L. (2014). In Elgowainy A., Dieffenthaler D., Sokolov V., Sabbisetti R., Cooney C. and Anjum A.(Eds.), GREET.NET model. (GREET v 1.2.0.11425 ed.). Lemont, IL.: Argonne National Laboratory.

UNDP. (2014). Country programme document for the state of kuwait (2015-2018) No. DP/DCP/KWT/2). Geneva: United Nation. 